\title{
Study and Analysis of Fuel Injection at Busemann Inlet at Mach 7
}

\author{
Kamal Darlami $^{1}$, Rajan Bhandari ${ }^{2,}$, , Abhishek Pandey ${ }^{2}$, Sanjeev Adhikari ${ }^{2}$, Sabin Subedi ${ }^{2}$ \\ ${ }^{1}$ Department of Mechanical and Aerospace Engineering, Pulchowk Campus, Institute of Engineering, Tribhuvan University, Kathmandu, \\ Nepal \\ ${ }^{2}$ Department of Mechanical Engineering, Thapathali Campus, Institute of Engineering, Tribhuvan University, Kathmandu, Nepal
}

Email address:

darlami.kd@pcampus.edu.np (K. Darlami), rajanbhandari9100@gmail.com (R. Bhandari), pandey.abhishek2054@gmail.com (A. Pandey), 071bme435sanjeev@ioe.edu.np (S. Adhikari)

*Corresponding author

\section{To cite this article:}

Kamal Darlami, Rajan Bhandari, Abhishek Pandey, Sanjeev Adhikari, Sabin Subedi. Study and Analysis of Fuel Injection at Busemann Inlet at Mach 7. American Journal of Mechanics and Applications. Vol. 8, No. 3, 2020, pp. 33-39. doi: 10.11648/j.ajma.20200803.11

Received: November 18, 2020; Accepted: December 1, 2020; Published: December 16, 2020

\begin{abstract}
The incomplete mixing of fuel and the drag induced in the engine are the main problems encountered in scramjets. Proper mixing of fuel can be achieved if the fuel is injected from the inlet of the engine. The fluid domain of Busemann Inlet at Mach 7 with boundary layer fuel injection using slot injectors along the wall was simulated with hydrogen fuel. Static pressure ratio at throat and inlet, along with Mach number at the throat were the design parameters of the Busemann inlet. Hydrogen fuel injection at two different equivalence ratios (0.3 and 0.7) was simulated successively at a temperature of $100 \mathrm{~K}$ and Mach 2.5 . The state of mixing was studied for three different injection angles $\left(30^{\circ}, 45^{\circ}\right.$, and $\left.60^{\circ}\right)$ for different equivalence ratios. The injection angles do not have a substantial effect on the hydrogen fuel mixing with the mainstream flow for equivalence ratio 0.3 Whereas, the dispersion of fuel increases as the increase in injection angles for equivalence ratio 0.7. But the total pressure recovery is maintained to the design value for equivalence ratio 0.3 rather than 0.7 . Similarly, $45^{\circ}$ fuel injection maintains a higher total pressure recovery than in other injection angles of $30^{\circ}$ and $60^{\circ}$. Injection technique other than slot injection can be used to study further the effect of fuel mixing in Busemann Inlet.
\end{abstract}

Keywords: Busemann Inlet, Hypersonic, Equivalence Ratio, Fuel Injection, Mass Fraction

\section{Introduction}

Scramjets are very far from commercial use but may have a large impact on space travel and military applications. The main motive of the space industry to work on this engine is due to its higher specific impulse than the contemporary rocket engines at higher Mach numbers. These engines can be used as Two Stage to Orbit (TSTO) in future rockets. They are lighter in weight due to no moving components and are environmentally friendly as the exhaust is water rather than carbon compounds. These features of scramjet have increased interest in it significantly. But, the main problem of a scramjet is the inefficient fuel injection. The fuel injection at the inlets has been studied to improve the mixing of fuel and efficiency of combustion in high-speed engines [1]. Inlet injection gained attention after Bushnell found out that problems such as flame retention, ignition, poor combustion efficiency, higher emission, etc. have occurred during mixing and combustion in Hypersonic air-breathing vehicles. [2]. This may increase fuel-efficiency along with engine efficiency. The main challenge in fuel injection via inlet is to prevent the pre-ignition of hydrogen fuel in the inlet. The basic assumptions in this study are that the aircraft is assumed to cruise at an altitude of $25 \mathrm{~km}$ and the air consists of nitrogen and oxygen only. The wall temperature of the inlet is assumed to be constant throughout. In Scramjet technology, the most challenging technical difficulties lie in fuel-air mixing as the time of resident of the air inside the engine is typically in the order of microseconds during which it is important to mix and burn the fuel and air. [3]. Drag values are very large at high Mach numbers and it is tedious to add extra kinetic energy to an airstream that is already energized. In terms of its thrust and drag elements, this 
implies that the engine is finely balanced and a low-drag output is necessary for success. Therefore, it can be understood that good conversion of the chemical energy of the fuel is necessary; but air passes through the engine in about a millisecond at high Mach, implying that the fuel must combine with the air in a few microseconds, burn and release its energy. The fuel must be chemically combined at the molecular level within a limited period of time, literally a few microseconds, to achieve full energy extraction. Fuel mixing must be done without disrupting the flow that might increase the drag. For the fuel/air ratio, the optimal upper limit is the value corresponding to the complete burning of all the oxygen in the air with all the reactants present in the fuel.

\section{Literature Review}

Fuel injection technique into scramjet engines is an emerging field of research. The fuel that scramjets use is usually either liquid or gas. An approximate stoichiometric proportion of fuel and air is needed to be mixed for efficient combustion. The main challenge of fuel injection in hypersonic engine is the negligible time for fuel to blend with mainstream air in exceptionally quick moving air. Hydrocarbons display more of a challenge to use due to the longer ignition delay and the necessity for more advanced mixing methods as compared to hydrogen. So, hydrogen is used as the main fuel of combustion. Improving the mixing, and hence decreasing the length of combustor, is an important factor in designing hypersonic engines. There are various types of methods to inject fuel in scramjet engine [4]:

1. Porthole Injection

2. Backward steps and cavities

3. Ramps

4. Strut injection

5. Film injection
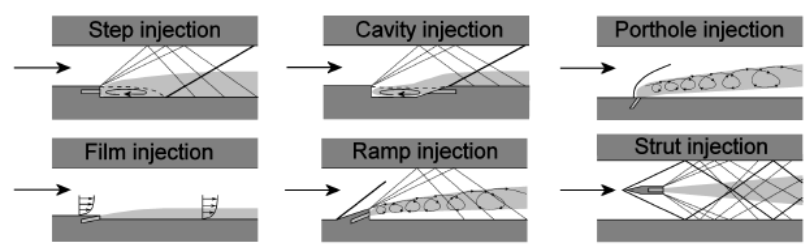

Figure 1. Methods of injecting fuel in a scramjet combustor [5].

Boundary layer combustion with slot injectors has also been studied to see their effects. Ngo has studied the results of injection and combustion on skin friction reduction via combustion in boundary layer [7]. The detailed study of slot injection parallel to a hypersonic mainstream is difficult due to the wave patterns superimposed upon a viscous mixing zone. This is because turbulent flows, particularly in the areas of mixing zones, involve turbulent modeling problems. [8]. There are different applications of slot injection such as prevention of separation, thermal protection, and reduction of skin friction [9]. The effects of large initial boundary layer thickness on the mainstream flow field are considerably important. For the cases where the ratio of the initial thickness of boundary-layer to the slot height is very large (greater than 1). In such condition, the initial boundary layer plays an important role in the development of slot injection flow field, especially in the near field [4]. Foster and Engblom found that rectangular injectors that are longer in the streamwise direction yield substantially improved mixing over circular or diamond-shaped injectors for normal injection into a Mach 1.2 cross-flow. They postulated that the rise in mixing is due to increased vorticity output in the cross-section of the jet flow [10]. In a case applicable to inlet injection in scramjets, V. Wheatley and P. A. Jacobs studied the enhancement of mixing offered by rectangular injectors: oblique injection into a cross-flow with a high supersonic Mach number [6]. A sonic hydrogen jet was pumped into a supersonic air cross-flow at an angle of $45^{\circ}$ to the freestream through a $1^{*} \mathrm{~W}$ slot as shown in figure 2 [6].

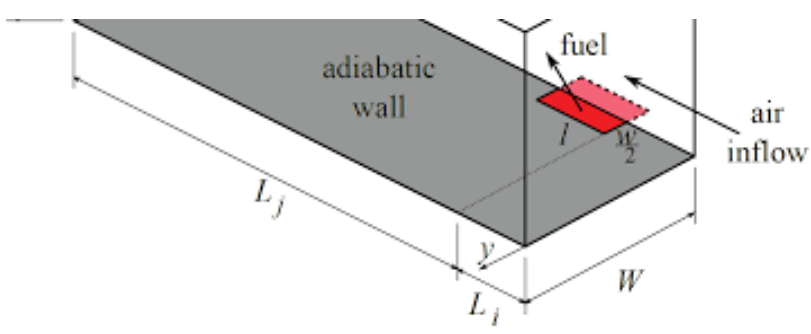

Figure 2. Simulation Geometry Including Coordinate System [6].

The simulation with and without infusion of hydrogen fuel along its body-side compression surface showed that the fuel cannot elude the body-side boundary layer that has small impact on macroscopic inlet flow structures at an equivalence ratio of 0.33 [11]. Macleod, C. and Gerrard, C. E. studied the mixing of air and fuel in supersonic combustor along with different methods of injection. They used simple injectors along with fins, struts, and pylons to study the fuel injection involving turbulence and swirl [12]. Similarly, Rogers, R. C. studied the jet penetration effects and its dependency on various parameters. They found that penetration was found to be proportional to the 0.3 power of the dynamic-pressure ratio at all downstream stations. The injection was performed perpendicular to the wall through a sonic nozzle [13].

\subsection{Influence of Injection Angle}

Several experiments have been performed in inclined cross-stream injection, with injection angles as low as $15^{\circ}$ to the wall level, and in both stream-wise and cross-stream injector planes. In all cases, near-field jet diffusion into the freestream is decreased relative to an equivalent regular jet. It is found that shallow injection angles further downstream from the injector resulted in better mixing and penetrated deep into the freestream in comparison to similar standard jet injector [4]. Because small freestream momentum input is necessary to transform the fuel downstream, it is assumed to be due to the jet maintaining a larger portion of its momentum normal to wall. Similarly, a slight reduction in overall viscous force is produced by the shallow injection angles than the 
larger injection angles.

\subsection{Inlet Injection}

Inlet injection requires the application of fuel injection from the hypersonic inlet compression surfaces. In the study of shock-induced combustion ramjets and detonation-wave, both of which target to reduce engine length, inlet fuel injection has also been used. It does so by using a powerful shock wave to initiate a detonation reaction of a properly mixed air-fuel stream, effectively removing the necessity for a combustor in the engine. Inlet injection has also been suggested as a way of enhancing the efficiency of conventional scramjets (non-detonation wave). By transferring the injectors upstream, the fuel and air are at least partially mixed before entering the combustion chamber. Compared to an in-combustor-only fuel arrangement, this decreases the necessary length of combustor necessary to contain the combustion of fuel fully. As skin friction drag can be responsible for more than 25 percent of total scramjet engine drag in the combustion chamber, reducing this length can contribute positively to the net thrust of the engine. However, as this can cause the engine to unstart, caution must be taken to prevent robust combustion at the inlet. The drag that could be caused by the engine inlet itself must be taken into account during injection from the inlet.

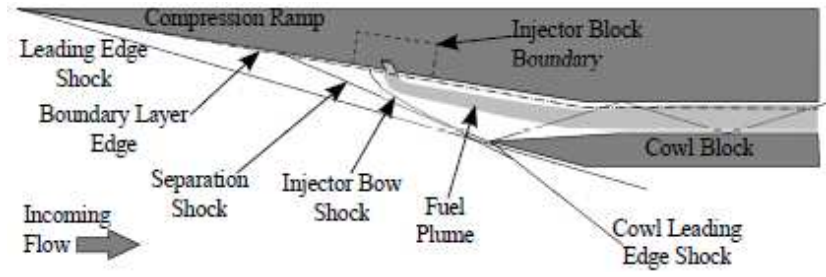

Figure 3. The experimental geometry of Gardner et al [14].

Inlet injection can also be beneficial because intense shock-wave interactions with reflected inlet leading-edge shocks at the entrance of combustor can improve the mixing of fuel. The fuel injection upstream of the combustion chamber was experimented with by Gardner, Paull and McIntyre [14]. The experimental pressure data shows that the fuel injected from the inlet did not ignite on the surfaces of the inlet, but ignited inside the combustion chamber. The thrust levels of the engine differed little with the change in inlet injectors angle, at varying angles of injection $25^{\circ}, 45^{\circ}$ and $90^{\circ}$ [14]. This showed that for inlet injection, oblique injection angles are highly desirable. In such situations, without adversely affecting combustion efficiency, the fuel jet itself may provide additional thrust. The mainstream fuel jet is far from the high-temperature boundary layer along the wall. In the inlet, the fuel is free from combustion since it does not exceed the combustion temperature. The fuel equivalence ratio plays a key role in preventing pre-combustion and unstarting the engine. A significant parameter to be considered is also the interaction of shock waves in fuel mixing. Shock waves affecting mixing regions have been shown to increase the overall diffusion of the flow where flame lengths have been found to decrease significantly [15].

\section{Methodology}

To observe the internal physics of flow of Mach 7 Busemann inlet with fuel injection, simulations were performed at three different injection angles for two different equivalence ratios. James E. Barth, Vincent Wheatley, and Michael K. Smart studied the effect of fuel injection along the REST inlet for an injection angle of $45^{\circ}$ and equivalence ratio 0.33 [11]. So, this study incorporated a larger domain for injection angles $\left(30^{\circ}, 45^{\circ}, 60^{\circ}\right)$ and equivalence ratios $(0.3$, 0.7). Slot injectors were used at a distance of $2.64 \mathrm{ft}$. from the intake of Busemann inlet. Taking benefit of the plane of symmetry in the Busemann inlet, half of the domain of flow was simulated using a commercial solver Fluent [16]. The outline of the position of the fuel inlet along the Busemann inlet is as shown in figure 4 .

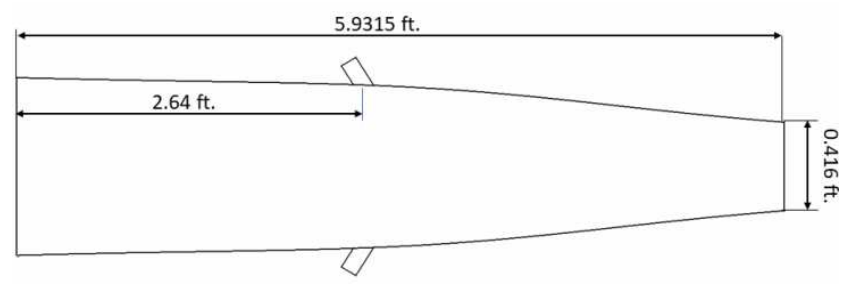

Figure 4. 2D-Busemann Inlet with fuel injector along the walls.

The inlet was designed for freestream Mach 7 with total pressure recovery 0.9776 , contraction ratio 11.83 , and static pressure ratio 37.8433 . The calculated radius at the throat of the Busemann inlet is $0.208 \mathrm{ft}$ and the length of intake is $5.9315 \mathrm{ft}$. The fuel injection parameters are as shown in table 1:

Table 1. Fuel Injection Parameters.

\begin{tabular}{lllll}
\hline & $\begin{array}{l}\text { Pressure } \\
\mathbf{( K P a )}\end{array}$ & $\begin{array}{l}\text { Mass flow rate at } \\
\mathbf{3 0}^{\circ}(\mathbf{k g} / \mathbf{s})\end{array}$ & $\begin{array}{l}\text { Mass flow rate } \\
\mathbf{a t} \mathbf{4 5}^{\circ}(\mathbf{k g} / \mathbf{s})\end{array}$ & $\begin{array}{l}\text { Mass flow rate } \\
\mathbf{a t} \mathbf{6 0}^{\circ}(\mathbf{k g} / \mathbf{s})\end{array}$ \\
\hline 0.3 & 30 & 0.08108 & 0.0737468 & 0.04284 \\
0.7 & 69.788 & 0.18919 & 0.172076 & 0.09996 \\
\hline
\end{tabular}

Similarly, the fuel parameters used in the study are as shown in table 2:

Table 2. Parameters of fuel.

\begin{tabular}{ll}
\hline Parameters & Value \\
\hline Molecular weight of Hydrogen Gas & $2.01588 \mathrm{gm} / \mathrm{moles}$ \\
Molecular weight of Oxygen Gas & $31.998 \mathrm{gm} / \mathrm{moles}$ \\
Radius of air inlet & $0.021785 \mathrm{~m}$ \\
Slot length of fuel inlet & $0.00057648 \mathrm{~m}$ \\
Radius of inlet at Injector & $0.195 \mathrm{~m}$ \\
Mass flow rate of air & $12.42 \mathrm{~kg} / \mathrm{s}$ \\
Mass flow rate of oxygen & $2.6082 \mathrm{~kg} / \mathrm{s}$ \\
Mass flow rate of hydrogen & $0.326025 \mathrm{~kg} / \mathrm{s}$ \\
Air mass flux rate & $83.7138 \mathrm{~kg} / \mathrm{m}^{2} / \mathrm{s}$ \\
Ratio of specific heats for Hydrogen $(\lambda)$ & 1.405 \\
Gas constant for Hydrogen $(\mathrm{R})$ & $4124.5 \mathrm{~J} / \mathrm{kgK}$ \\
Velocity of hydrogen fuel & $1903.04 \mathrm{~m} / \mathrm{s}$ \\
Density of hydrogen fuel & $8.727 \mathrm{~kg} / \mathrm{m}^{3}$ \\
Static Temperature $(K)$ & 100 \\
\hline
\end{tabular}


The simulation was carried out in the Busemann Inlet with a fuel injector at $2.64 \mathrm{ft}$. far from the intake of Busemann inlet as shown in figure 3 . The grid was generated using the commercial grid generating software called Pointwise [17]. The grid convergence was checked for viscous flow without fuel injection for three different meshes. The number of cells count was 21605,48836 , and 73647 . The criteria for mesh independence were taken within $1 \%$. The percentage of deviation of average outlet pressure of medium mesh with that of fine mesh was $0.13 \%$. So, the grid with 48836 was optimally fine for further simulation. The convergence criteria of $10^{-3}$ were set for the simulation along with double precision accuracy. The simulation was carried out using the k- $\omega$ (SST) Turbulence model.

\section{Results and Analysis}

Fuel injection at the intake of the Busemann inlet was done without considering chemical reaction as the study was concerned only with the mixing of hydrogen fuel. Mass fraction of $\mathrm{H}_{2}$, static temperature, static pressure at the throat of the inlet, and pressure recovery are the parameter analyzed after the simulation. The simulation for different equivalence ratios and different injection angles showed different results and contours.

Schlieren image of density contour in Figure 4 and Figure 5 shows different locations at the wall of the Busemann inlet where the Mach wave originates. Reflected shock is formed before the throat of the inlet which interacts with the shear layer to form vortices. This leads to fuel jet break up and aids in near field mixing [18]. Shock formed are converged at a point and then reflected, which strikes in front of the throat. The density gradient increases in the region of reflected shock as shown in figure 5 . The contours in figure 5 and figure 6 show that the density gradient for $\varphi=0.7$ is greater than $\varphi=0.3$, which illustrates that hydrogen fuel is more dispersed with an increase in equivalence ratio.

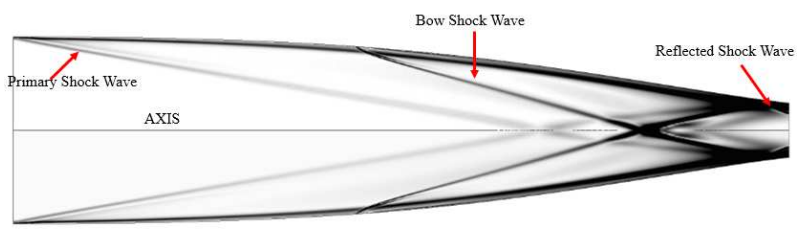

Figure 5. Schlieren Image at $\varphi=0.3$, injection angle $=30^{\circ}$
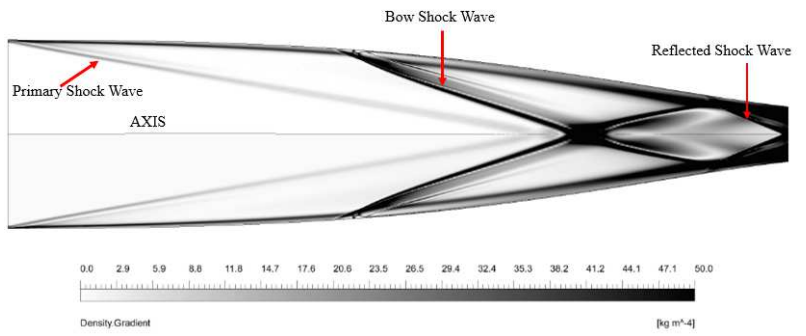

Figure 6. Schlieren Image at $\varphi=0.7$, injection angle $=60^{\circ}$.
Mach waves formed at different positions of the inlet. Shock is generated under reflection and it continuously interacts with the supersonic shear layer. This leads to the generation of small eddies through the baroclinic torque mechanism [19].

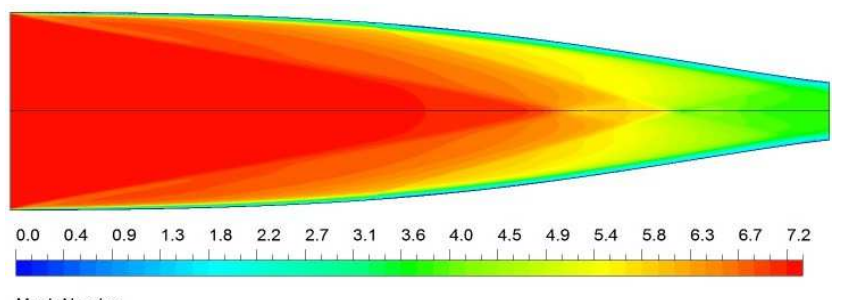

Mach Number

Figure 7. Mach number at $\varphi=0.3$, injection angle $=30^{\circ}$

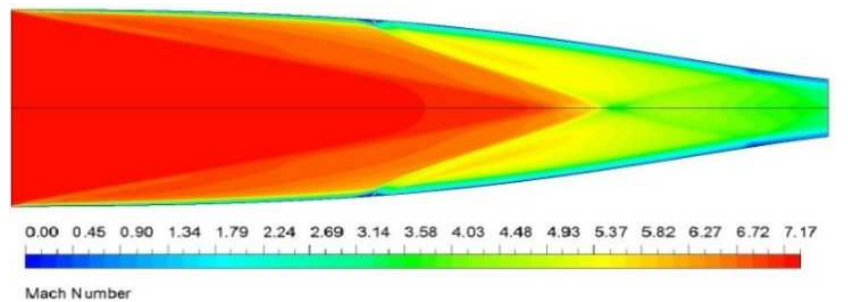

Figure 8. Mach number at $\varphi=0.7$, injection angle $=60^{\circ}$.

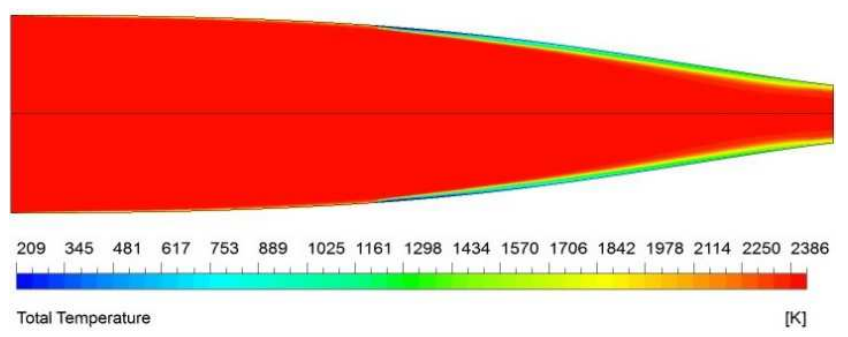

Figure 9. Total temperature contour at $\varphi=0.3$, injection angle $=30^{\circ}$.

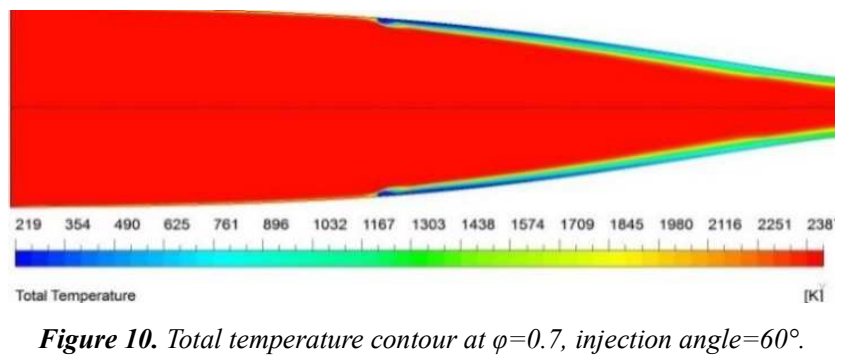

The total temperature at the wall of the inlet suddenly decreases in the interaction zone of fuel and inlet air as shown in Figure 9 and Figure 10. The total temperature along the wall continues to decrease from the fuel injector as shown in Figure 9 and Figure 10. This is due to the decrease in the Mach number of the mixture. Figure 11 and Figure 12 show the mass fraction of hydrogen along the wall which recedes along the wall towards the throat. Contours show that injected fuel remains attached to the boundary layer in case of injection angle $30^{\circ}$ and equivalence ratio 0.3 as shown in Figure 10 . Whereas in Figure 11 , at $60^{\circ}$ injection angle with an equivalence ratio of $0.7 \mathrm{H}_{2}$ gets dispersed more efficiently than at $30^{\circ}$ with an equivalence ratio of 0.3 .

The Mach number contours in Figure 7 and Figure 8 show the 


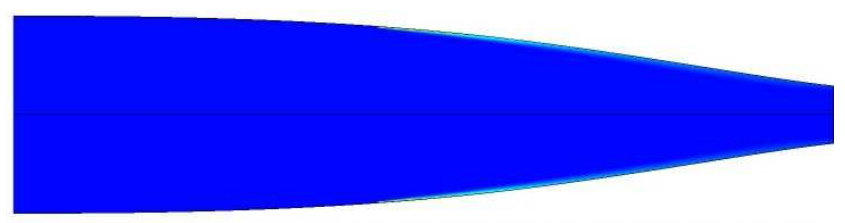

$\begin{array}{lllllllllllllllll}0.00 & 0.06 & 0.12 & 0.18 & 0.24 & 0.30 & 0.36 & 0.42 & 0.48 & 0.55 & 0.61 & 0.67 & 0.73 & 0.79 & 0.85 & 0.91 & 0.97\end{array}$

H2.Mass Fraction

Figure 11. $\mathrm{H}_{2}$ mass fraction at $\varphi=0.3$, injection angle $=30^{\circ}$.

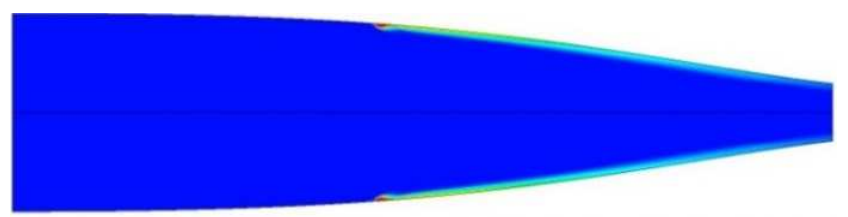

$\begin{array}{lllllllllllllllll}0.00 & 0.06 & 0.12 & 0.18 & 0.24 & 0.31 & 0.37 & 0.43 & 0.49 & 0.55 & 0.61 & 0.67 & 0.73 & 0.80 & 0.86 & 0.92 & 0.98\end{array}$ H2. Mass Fraction

Figure 12. $\mathrm{H}_{2}$ mass fraction at $\varphi=0.7$, injection angle $=60^{\circ}$.

The plot of $\mathrm{H} 2$ mass fraction at injection angles of $30^{\circ}, 45^{\circ}$, and $60^{\circ}$ at equivalence ratio 0.3 shows that $\mathrm{H}_{2}$ fuel has not dispersed properly as the mass fraction tends to zero near the symmetric axis away from the walls. Similarly, the change in injection angle does not show much difference in the distribution of $\mathrm{H}_{2}$ fuel which can be seen in figure 13 .

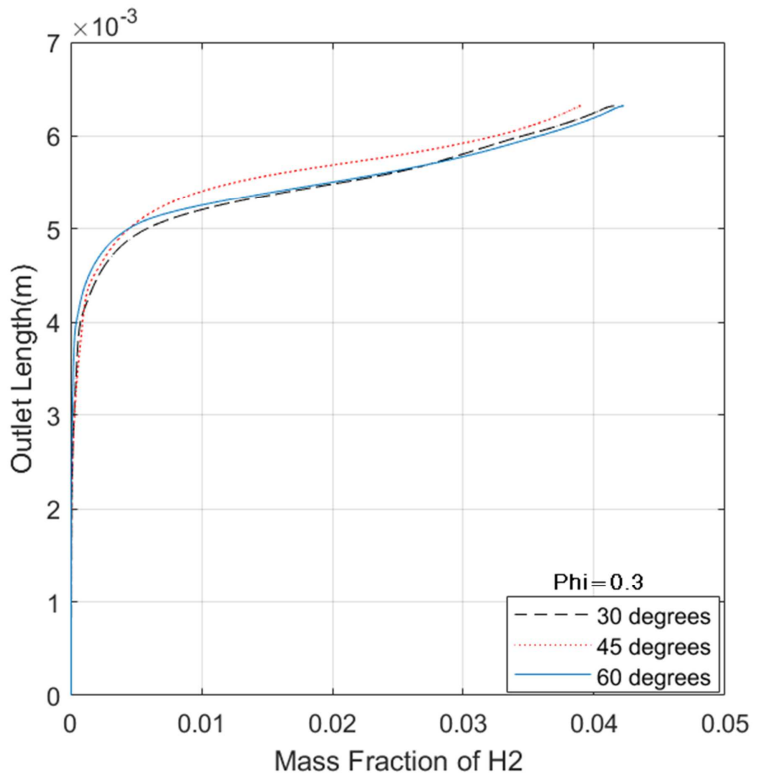

Figure 13. Variation of mass fraction of $\mathrm{H}_{2}$ along the outlet at $\varphi=0.3$.

The important performance parameter of Busemann geometry is its total pressure recovery which is 0.97 . So, it is necessary to study the total pressure recovery when fuel is injected. The total pressure recovery for different equivalence ratios and different injection angles are shown in Figure 14. Figure 14 shows the variation of total pressure recovery which is the performance parameter of the intake. It shows that with the increase in equivalence ratio total pressure recovery of the intake decreases. However, an increase in the injection angle increases the total pressure recovery until $45^{\circ}$ and decreases gradually as shown in figure 14 for any equivalence ratio.

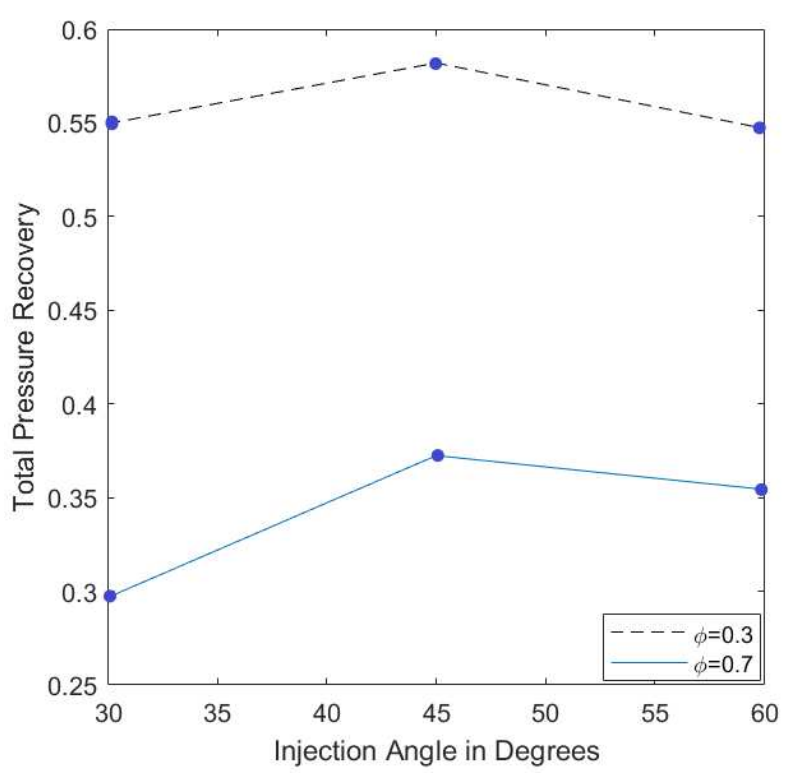

Figure 14. Total pressure recovery plot for different cases.

Similarly, simulation at different injection angles at an equivalence ratio of 0.7 is computed which shows an increase in the mixing of $\mathrm{H}_{2}$ fuel at $60 \mathrm{o}$ along the outlet. Whereas, the mass fraction of $\mathrm{H}_{2}$ at $30^{\circ}$ is maximum along the boundary layer and is quite less away from the wall which can be seen in Figures 11 and 12. From comparative analysis at different equivalence ratios, it is concluded that the mixing of $\mathrm{H}_{2}$ is not affected by the injection angles when the equivalence ratio is 0.3 as shown in figure 12 . Whereas, in the case of equivalence ratio 0.7 , the dispersion of $\mathrm{H}_{2}$ is more when the injection angle increases which is clearly shown in figure 15 . But in overall the mixing is quite poor because the maximum value of the mass fraction is about 0 towards the symmetric plane of the inlet while its maximum along the wall.

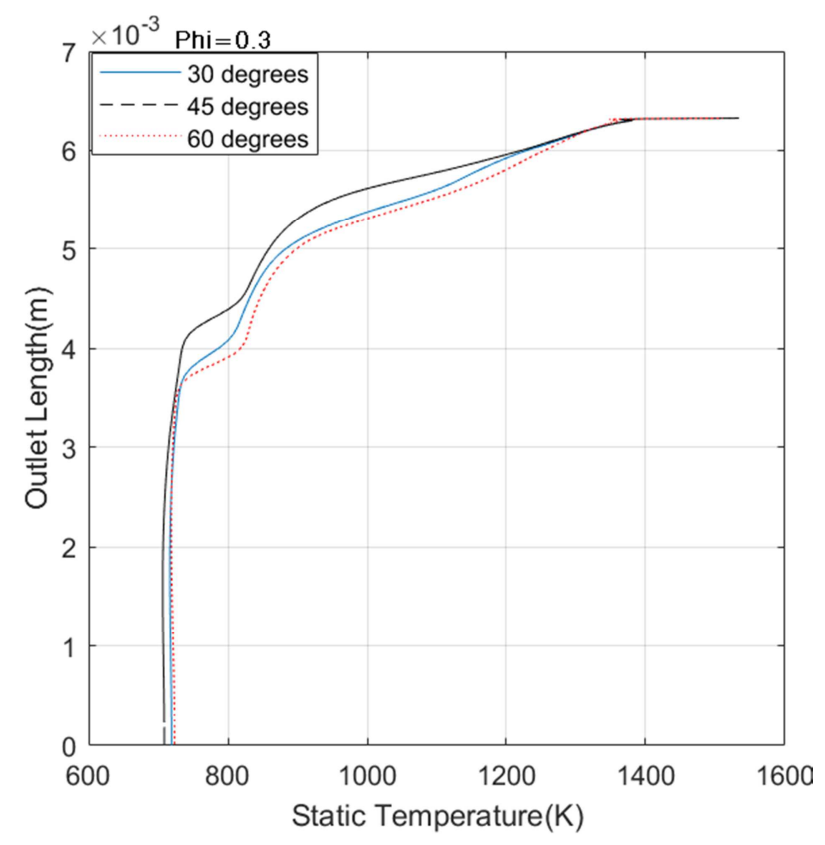

Figure 15. Variation of mass Fraction of $\mathrm{H}_{2}$ along the outlet at $\varphi=0.7$. 
Moreover, Figures 16 and 17 shows the variation of static temperature along the outlet for different injection angles at equivalence ratios of 0.3 and 0.7 . The static temperature plot along the outlet shows that the temperature of the mixture is below the ignition temperature of hydrogen gas. This concludes that there is no pre-ignition or pre-combustion of hydrogen fuel at the throat. At $\varphi=0.7$ static temperature along the outlet decreases than at $\varphi=0.3$, which signifies that the dispersion of $\mathrm{H}_{2}$ is more at $\varphi=0.7$.

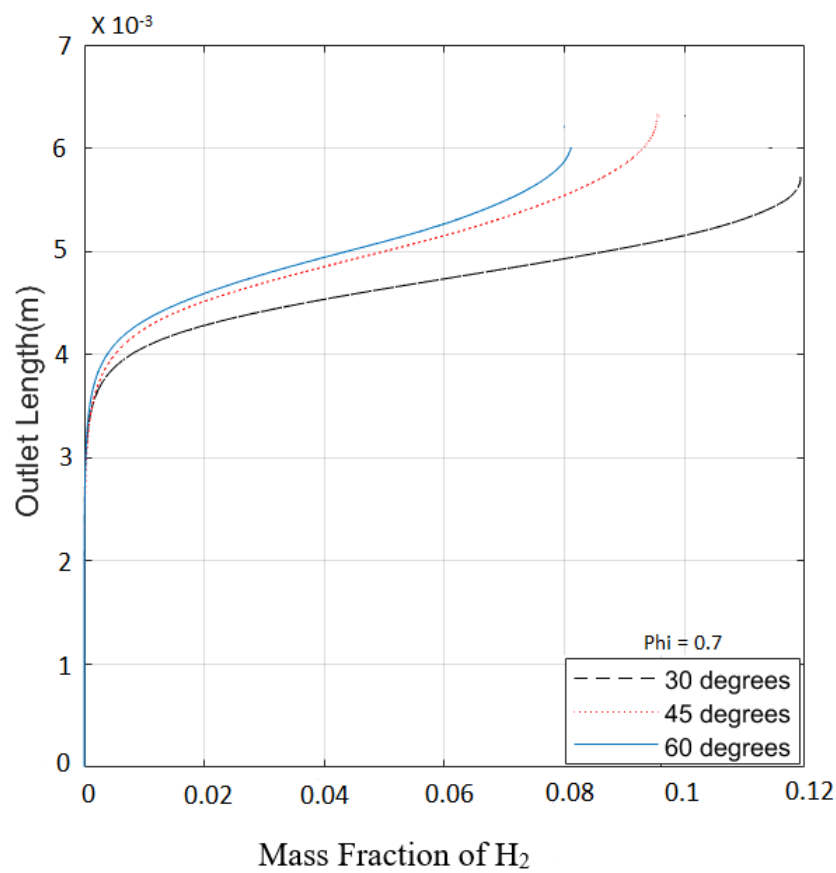

Figure 16. Static temperature along the outlet for different injection angles at $\varphi=0.3$.

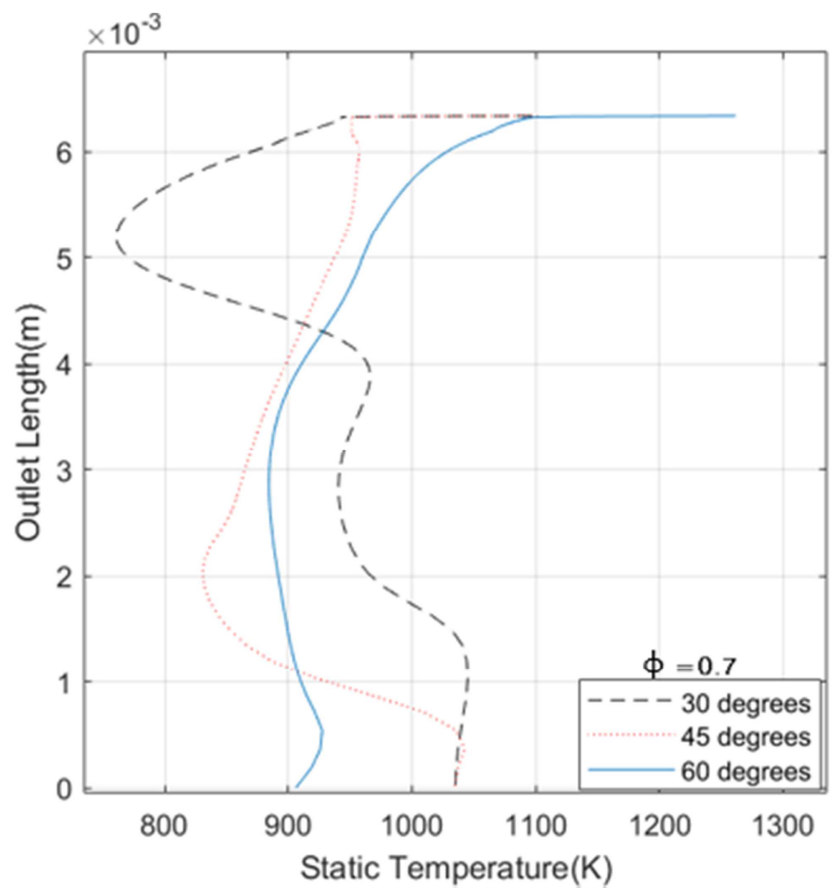

Figure 17. Static temperature along the outlet for different injection angles at $\varphi=0.7$.

\section{Conclusions}

The viscous simulation using the k- $\omega$ (SST) scheme helped to capture the boundary layer in the walls. The validation of the results in the viscous simulation is done through the mesh convergence criterion of $( \pm 1 \%)$. The injection angle of 300 , $45^{\circ}$, and $60^{\circ}$ is used to study the mass fraction at different locations along the outlet. As the fuel injection along the walls of Busemann Inlet is free from pre-ignition, it is safe to inject fuel at the inlet of the engine. But, for an equivalence ratio of 0.7 , the mass fraction of $\mathrm{H}_{2}$ is found to be maintained near the walls and is quite small away from the wall. Similarly, the mass fraction of $\mathrm{H}_{2}$ at the outlet near the wall is about $5 \times 10^{-3}$ and the mass fraction far away from the wall is very less, near to $10^{-3}$ for almost every injection angles. Similarly, in the case of equivalence ratio 0.3 for different injection angles the mass fraction of about $4 \times 10^{-2}$ is found near the wall along the outlet while the value is near to 0 away from the wall. A higher equivalence ratio helps in better dispersion of fuel than in the case of a lower equivalence ratio. To conclude, the fuel resided along the wall as it could not penetrate the boundary layer along the wall and proper mixing could not be achieved. The slot injectors are not recommended to use for further study of fuel injection as does not help in the proper mixing of fuel. Injectors other than slot injector is recommended for fuel injection as the fuel-injected through slot injectors could not penetrate the boundary layer of air and proper mixing of fuel could not be obtained.

\section{Acknowledgements}

This study was supported by Department of Mechanical Engineering, Thapathali Campus for providing resources at the initial phase of the study. IIEC, Pulchowk Campus did a great job facilitating us with a high performing computer. Asst. Prof. Sudip Bhattarai owes a great thankfulness for helping out throughout the study.

\section{References}

[1] J. Sislian, "Scramjet Propulsion: Detonation-Wave Ramjets," Progress in Astronautics and Aeronautics., vol. 189, pp. 823-889, 2000.

[2] D. M. Bushnell, "Mixing and Combustion Issues in Hypersonic Air-Breathing Propulsion," Combustion in high-speed flows., pp. 3-16, 1994.

[3] D. M. Van Wie, S. M. D'Alessio and M. E. White, "Hypersonic airbreathing propulsion.," Johns Hopkins APL technical digest, vol. 26, no. 4, pp. 430-437, 2005.

[4] J. Barth, "Mixing and combustion enhancement in a Mach 12 shape-transitioning," 2014.

[5] J. Turner, "An Experimental Investigation of Inlet Fuel Injection in a Three- Dimensional Scramjet Engine," 2010.

[6] V. Wheatley and P. A. Jacobs, "Fuel injection via rectangular crosssection injectors for mixing enhancement in scramjets.," in 17th Australasian Fluid Mechanics Conference 2010, 2010. 
[7] T. K. Ngo, "Effect of injection strategy and mainstream combustion on skin friction reduction through boundary layer combustion in scramjet combustors.," 2016.

[8] F. Billig, J. Schetz and S. Favin, "Analysis of slot injection beneath a thick hypersonic boundary layer," in 25th Joint Propulsion Conference, 1991.

[9] F. Billig, J. Schetz and S. Favin, "Gaseous injection in high speed flow," in International Symposium on Air Breathing Engines, Athens, Greece, 1989.

[10] L. Foster and W. Engblom, "Computation of Transverse Injection into Supersonic Crossflow with Various Injector Orifice Geometries.," in 42nd AIAA Aerospace Sciences Meeting and Exhibit, 2004.

[11] J. E. Barth, V. Wheatley and M. K. Smart, "Effects of hydrogen fuel injection in a Mach 12 scramjet inlet," AIAA Journal 53.10, pp. 2907-2919, 2015.

[12] C. Macleod and C. E. Gerrard., "A review of air-fuel mixing and alternative methods in scramjets and scramjet-like engines," Journal of the British Interplanetary Society, vol. 69, no. $4,2016$.

[13] R. C. Rogers, A study of the mixing of hydrogen injected normal to a supersonic airstream, National Aeronautics and Space Administration, 1971.

[14] A. D. Gardner, A. Paull and T. J. McIntyre., "Upstream porthole injection in a 2-D scramjet model," Shock Waves, vol. 11, no. 5, pp. 369-375, 2002.

[15] H. Huh and J. F. Driscoll, "Shock-wave-enhancement of the mixing and the stability limits of supersonic hydrogen-air jet flames," Symposium (International) on Combustion, vol. 26, no. 2, pp. 2933-2939, 1996.

[16] Ansys Fluent, Software Package, Ver. 19.1, Ansys, Pennsylvania, United States.

[17] Pointwise, Software Package, 18.0 R3, Pointwise Inc., Texas, United States.

[18] Soni, R. Kumar and A. De, "Investigation of strut-ramp injector in a Scramjet combustor: Effect of strut geometry, fuel and jet diameter on mixing characteristics.," Journal of Mechanical Science and Technology, vol. 31, no. 3, pp. 1169-1179, 2017.

[19] Y. Andreopoulos, J. H. Agui and G. Briassulis, "Shock wave - turbulence interactions.," Annual Review of Fluid Mechanics, vol. 32, no. 1, pp. 309-345, 2000. 